\title{
Soluble HLA G serum levels in patients with the Acquired Immunodeficiency Syndrome affected by different AIDS-defining conditions before and after anti-retroviral treatment
}

\author{
G. Murdaca*, P. Cagnati, F. Puppo \\ Department of Internal Medicine, University of Genoa, Viale Benedetto XV 6, 16132 Genoa, Italy \\ * giuseppe.murdaca@unige.it
}

KEYWORDS: Soluble HLA-G molecules, opportunistic infections, Kaposi's sarcoma, AIDS, HAART.

\begin{abstract}
We have previously reported that serum levels of soluble $H L A-A,-B,-C$ and $-G$ antigens are elevated in HIV-infected subjects and decrease after antiretroviral therapy. In this study we measured soluble HLA-G serum levels in patients with AIDS affected by different AIDS-defining conditions before and during antiretroviral therapy and correlated them with virological and immunological parameters. Soluble HLA-G levels were significantly higher in AIDS patients before treatment as compared to healthy controls and significantly decreased after 36 months of therapy, correlating with the decrease of plasma HIV-RNA level and CD8+ T-lymphocytes number and with the increase of CD4+ T-lymphocytes number. Soluble HLA-G levels were significantly higher in patients with opportunistic infections and Kaposi's sarcoma as compared with those with wasting syndrome. These data suggest that infections and neoplasms may trigger the shedding of soluble HLA-G molecules and confirm that the level of soluble HLA-G in serum might represent a surrogate marker to monitor virological response and immune reconstitution in HIV-positive subjects.
\end{abstract}

\section{Introduction}

The human major histocompatibility complex (HLA) encodes two sets of HLA class I molecules, which have been termed class la (HLA-A, -B and -C or classical) and class $\mathrm{lb}$ (HLA-E, $-\mathrm{F}$ and $-\mathrm{G}$ or non-classical) molecules. The class la antigens have a broad tissue expression and a high degree of polymorphism [1] whereas the class $\mathrm{lb}$ antigens are characterized by a restricted tissue distribution and by a limited polymorphism [2].
HLA molecules are composed of a 44-kD polymorphic glycoprotein (heavy chain) non-covalently associated with a $12-k D$ invariant protein ( $\beta_{2}$-microglobulin). Besides being expressed as membrane bound proteins, HLA molecules are found in serum in soluble form (sHLA) $[3,4]$. In particular, amongst the seven HLA-G isoforms generated by alternative splicing of the primary HLA-G transcript, three (HLA-G5, -G6 and -G7) are detectable soluble form $[5,6]$. The serum level of $b_{2}$-microglobulin is increased in patients with human immunodeficiency virus (HIV) -1 infection and has been proposed as a surrogate marker of disease progression [7,8]. We have previously reported that the serum levels of sHLA-A, $-B,-C$ and sHLA-G are significantly elevated in HIV-infected subjects as compared to HIV-negative controls, that their increase correlates with disease progression and development of the Acquired Immunodeficiency Syndrome (AIDS), and that their decrease significantly correlates with virological and immunological response to Highly Active Antiretroviral Therapy (HAART) [8-10].At present, it is not known if sHLA-G serum levels may differ among patients with the AIDS suffering from different AIDS-defining conditions. Therefore, in the present study, we measured sHLA-G serum levels in AIDS patients affected by five different AIDS-defining conditions before and during HAART and correlated them with virological and imunological parameters of response to anti-viral treatment.

\section{Materials and Methods}

Patients

Sixty-eight patients with AIDS (CDC stage C) were consecutively enrolled in our centre for immunodeficiency diseases (Tab.1). Sixty-eight age- and sex-matched healthy donors served as controls. Patients were treated with highly active antiretroviral therapy (HAART) according to the Department of Health and Human Services (DHHS) guidelines utilizing the drugs available at the time of their enrolment.

Lymphocyte membrane phenotype and plasma HIV-RNA levels were evaluated at baseline $\left(T_{0}\right), 3$ and 6 months after starting antiretroviral treatment $\left(T_{3}\right.$ and $\left.T_{6}\right)$, then every 6 
Soluble HLA G serum levels in patients with the Acquired Immunodeficiency Syndrome

\begin{tabular}{|c|c|c|c|c|c|}
\hline \multicolumn{6}{|c|}{ AIDS defining conditions } \\
\hline & $\begin{array}{l}\text { Candida } \\
\text { esophagitis }\end{array}$ & $\begin{array}{l}\text { Gastrointestinal } \\
\text { Cryptosporidiosis }\end{array}$ & $\begin{array}{c}\text { Pneumocystis jirovecii } \\
\text { pneumonia }\end{array}$ & Kaposi's sarcoma & Wasting syndrome \\
\hline No & 20 & 12 & 10 & 10 & 16 \\
\hline Male/Female & $11 / 9$ & $7 / 5$ & $6 / 4$ & $6 / 4$ & $8 / 8$ \\
\hline Age (mean $\pm S D)$ & $39.2 \pm 8.1$ & $40.1 \pm 7.8$ & $39.8 \pm 8.3$ & $39 \pm 8.5$ & $40.2 \pm 8.6$ \\
\hline Drug user (male/female) & $8 / 6$ & $4 / 3$ & $4 / 1$ & $2 / 3$ & $4 / 6$ \\
\hline $\begin{array}{l}\text { Heterosexual } \\
\text { (male/female) }\end{array}$ & $2 / 3$ & $2 / 2$ & $1 / 3$ & $\mathrm{I} / \mathrm{I}$ & $2 / 2$ \\
\hline Male homosexual & 1 & 1 & 1 & 3 & 2 \\
\hline $\begin{array}{l}\text { CD4 cells/ } \mu \mathrm{l} \\
\text { mean }(\mathrm{Cl})\end{array}$ & $\begin{array}{c}160 \\
(129-192) \\
\end{array}$ & $\begin{array}{c}159 \\
(112-207) \\
\end{array}$ & $\begin{array}{c}34 \\
(15-52) \\
\end{array}$ & $\begin{array}{c}60 \\
(28-92) \\
\end{array}$ & $\begin{array}{c}185 \\
(161-209) \\
\end{array}$ \\
\hline $\begin{array}{l}\text { CD4 \% } \\
\text { mean }(\mathrm{Cl})\end{array}$ & $\begin{array}{c}9.7 \\
(9.1-10.3) \\
\end{array}$ & $\begin{array}{c}9.8 \\
(9.2-10.5) \\
\end{array}$ & $\begin{array}{c}9.5 \\
(8.4-10.6) \\
\end{array}$ & $\begin{array}{c}9.4 \\
(8.2-10.5) \\
\end{array}$ & $\begin{array}{c}9.7 \\
(8.9-10.4) \\
\end{array}$ \\
\hline $\begin{array}{l}\text { CD8 \% } \\
\text { mean }(\mathrm{Cl})\end{array}$ & $\begin{array}{c}54.3 \\
(52.7-55.8) \\
\end{array}$ & $\begin{array}{c}54.7 \\
(52.7-56.6) \\
\end{array}$ & $\begin{array}{c}54.8 \\
(52.5-57.1) \\
\end{array}$ & $\begin{array}{c}54.7 \\
(52.4-56.9)\end{array}$ & $\begin{array}{c}55 \\
(53.3-56.7) \\
\end{array}$ \\
\hline $\begin{array}{l}\text { HIV-RNA } \\
\text { copies/mI } \\
\text { mean }(\mathrm{Cl})\end{array}$ & $\begin{array}{c}11766 \\
(4954-27917)\end{array}$ & $\begin{array}{c}36279 \\
(22337-58865)\end{array}$ & $\begin{array}{c}64796 \\
(39696-105873)\end{array}$ & $\begin{array}{c}60961 \\
(34544-107689)\end{array}$ & $\begin{array}{c}34030 \\
(19341-59874)\end{array}$ \\
\hline
\end{tabular}

Table 1. Characteristics of AIDS patients. Cl: confidence intervals

months up to 24 months ( $\left(\mathrm{T}_{2}\right.$, to $\left.\mathrm{T}_{24}\right)$ and, finally, after 36 months of HAART $\left(T_{36}\right)$. sHLA-G antigens serum levels were determined at $T_{0}$ and every 6 months after starting antiretroviral therapy up to 24 months ( $\mathrm{T}_{6}$ to $\mathrm{T}_{24}$ ) and, finally, after 36 months of HAART $\left(T_{36}\right)$.

\section{Lymphocyte membrane phenotype}

Lymphocyte membrane phenotype was evaluated by means of whole blood direct immunofluorescence technique and flow cytometric analysis as described previously [16,17]. Results were expressed as percentage and absolute number (cells/ $/$ l) of CD4+ and as percentage of CD8+ cells.

\section{Plasma HIV-RNA}

Plasma HIV-RNA level was evaluated by a quantitative reverse transcriptase polymerase chain reaction assay (Nuclisens HIV-1 QT, Biomerieux, Marcy L'Etoile, France). Results were expressed as copies $/ \mathrm{ml}$ and levels $\leq 80$ copies/ $\mathrm{ml}$ were considered as undetectable for statistical analysis.

\section{sHLA-G molecules}

sHLA-G serum level was determined by a double determinant enzyme immunoassay utilizing a commercially available kit (EXBIO Praha a.s., Vestec, Czech Republic). Results were expressed as $\mathrm{ng} / \mathrm{ml}$.

\section{Statistical analysis}

Results are expressed as means and $95 \%$ confidence intervals $(\mathrm{Cl})$. The HIV-RNA levels did not follow the normal distribution and were log-transformed to be analysed with parametric test. Means and $\mathrm{Cl}_{95 \%}$ were obtained by exponentiating values derived from elaboration of log-transformed data. Analysis of variance was used to calculate the differences between HIV-infected patients group and healthy controls group and between genders and different AIDS-defining conditions at $T_{0}$. HIV-RNA levels at $T_{0}$ were compared with those at the following times by paired t-test. The comparisons among value profiles through the experimental period were performed using the two factor (diagnosis and gender) analysis of variance for repeated measures, with Scheffe's internal comparisons and interaction terms. The correlations were calculated by Pearson's correlation coefficients ( $r$ ) assembling data of all times. The significance level was taken as $a=0.05$.

\section{Results}

\section{Lymphocyte membrane phenotype}

Mean percentage and absolute number of CD4+ T-lymphocytes significantly increased from $\mathrm{T}_{0}(9.6 \% ; \mathrm{Cl}: 9.3$ 9.9 and 132 cells $/ \mathrm{ml} ; \mathrm{Cl}: 114-152)$ to $\mathrm{T}_{36}(23.6 \%$; Cl: $23.4-$ 23.8 and 614 cells $/ \mathrm{ml} ; C l: 569-659)(P<0.0001)$ whereas mean percentage of CD8+ $\mathrm{T}$ lymphocytes significantly decreased from $\mathrm{T}_{0}(54.6 \% ; \mathrm{Cl}: 53.9-55.4)$ to $\mathrm{T}_{36}(26.4 \% ; \mathrm{Cl}$ : 25.7-27.1) $(P<0.0001)$.

\section{Plasma HIV-RNA level}

Mean plasma HIV-RNA level was 30,152 copies $/ \mathrm{ml}(\mathrm{Cl}$ : $21,612-42,108)$ at $T_{0}$ and became undetectable $(\leq 80$ copies $/ \mathrm{ml}$ ) in 51 and 17 patients at $\mathrm{T}_{3}$ and at $\mathrm{T}_{6}$, respectively. 145 
Then, plasma HIV-RNA level remained undetectable in all patients up to $T_{36}\left(P<0.0001\right.$ as compared to $\left.T_{0}\right)$.

\section{sHLA-G level}

Mean sHLA-G level at baseline was significantly higher in AIDS patients (55.77 ng/ml; $\mathrm{Cl}: 49.71-61.83)$ as compared to healthy controls $(9.26 \mathrm{ng} / \mathrm{ml} ; \mathrm{Cl}: 8.43-10.17)(\mathrm{P}<0.0001)$ and significantly decreased after 36 months of HAART (17.64 $\mathrm{ng} / \mathrm{ml} ; \mathrm{Cl}: 14.37-20.90 ; \mathrm{P}<0.0001)$. Of note, mean sHLA-G level at $T_{0}$ was significantly higher in patients with Candida esophagitis (77.87 ng/ml; Cl: 68.20-87.53), gastrointestinal Cryptosporidiosis ( $56.86 \mathrm{ng} / \mathrm{ml}$; Cl: 50.78-62.97), Kaposi's sarcoma (56.99 ng/ml; Cl: 44.45-69.52) and Pneumocystis jirovecii pneumonia $(64.33 \mathrm{ng} / \mathrm{ml} ; \mathrm{Cl}: 61.02-67.65)$ as compared to subjects with wasting syndrome $(21.23 \mathrm{ng} / \mathrm{ml} ; \mathrm{Cl}: 19.08-23.38)$ $(P<0.0001)$. Moreover, mean sHLA-G level at $T_{36}$ remained significantly higher in patients with Candida esophagitis (25.65 $\mathrm{ng} / \mathrm{ml}$; Cl: 17.73-33.57), gastrointestinal Cryptosporidiosis (19.42 ng/ml; Cl: 12.78-26.06) and Pneumocystis jirovecii pneumonia $(23.40 \mathrm{ng} / \mathrm{ml} ; \mathrm{Cl}: 20.64-26.16)$ as compared to subjects with wasting syndrome $(3.81 \mathrm{ng} / \mathrm{ml}$; Cl: 2.44-5.18; $p<0.0001, p=0.0115$ and $p=0.0015$, respectively). Mean sHLA-G level at $T_{36}$ was also higher in patients who developed Kaposi's sarcoma (15.83 ng/ml; Cl: 10.18-21.48) as compared to subjects with wasting syndrome although the difference did not reach the statistical significance $(p=0.124)$ (Fig. 1$)$.

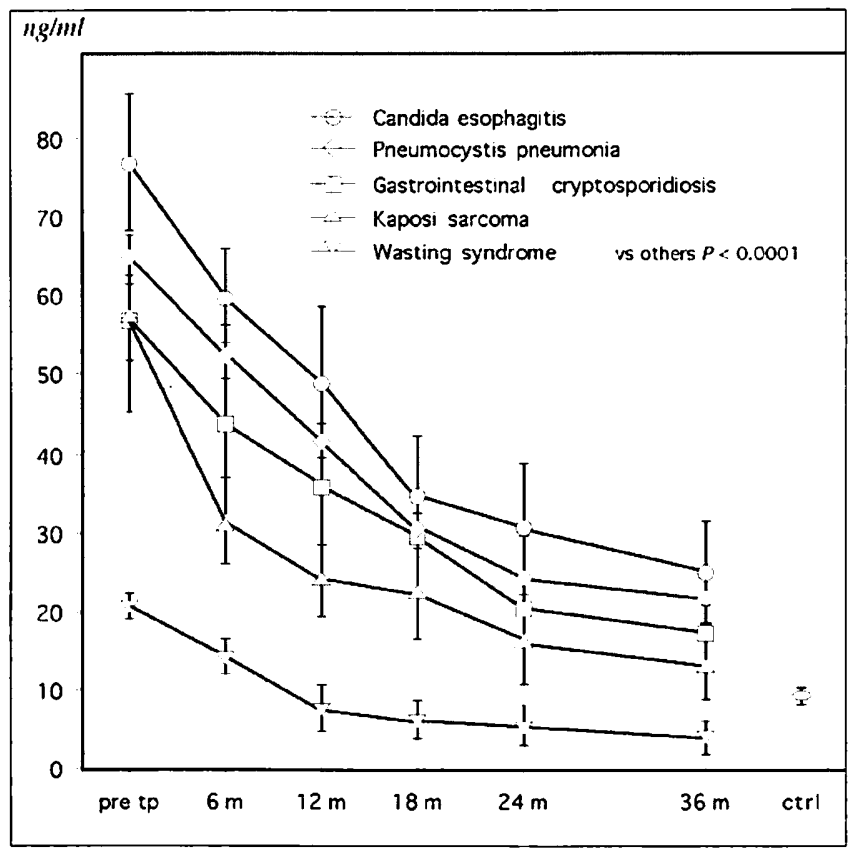

Figure 1. Mean sHLA-G serum levels in AIDS patients with different AIDSdefining conditions before and after ontiretroviral treatment ( $m$ : months).

The decrease of sHLA-G levels significantly correlated with the decrease of plasma HIV-RNA levels $\left(r_{s}: 0.455, P<0.0001\right)$, particularly in patients who developed Pneumocystis jirovecii pneumonia $\left(r_{s}: 0.797, P<0.0001\right)$ and Kaposi's sarcoma $\left(r_{s}\right.$ : $0.765, P<0.0001)$. Furthermore, an inverse correlation was found between sHLA-G levels and the percentage and absolute number of CD4+ T-lymphocytes (sHLA-G vs. CD4+ percentage: $r_{s}:-0.519, P<0.0001$; sHLA-G vs. CD4+ absolute number: $r_{s}:-0.403, P<0.0001$ ) (Fig.2), especially in subjects with Pneumocystis jirovecii pneumonia (sHLA-G vs. CD4+ percentage: $r_{s}:-0.903, P<0.0001 ; s H L A-G$ vs. CD4+ absolute number: $\left.r_{s}:-0.781, P<0.0001\right)$. By contrast, a positive correlation was found between sHLA-G levels and the percentage of CD8+ T-lymphocytes $\left(r_{s}: 0.448, P<0.0001\right)$.

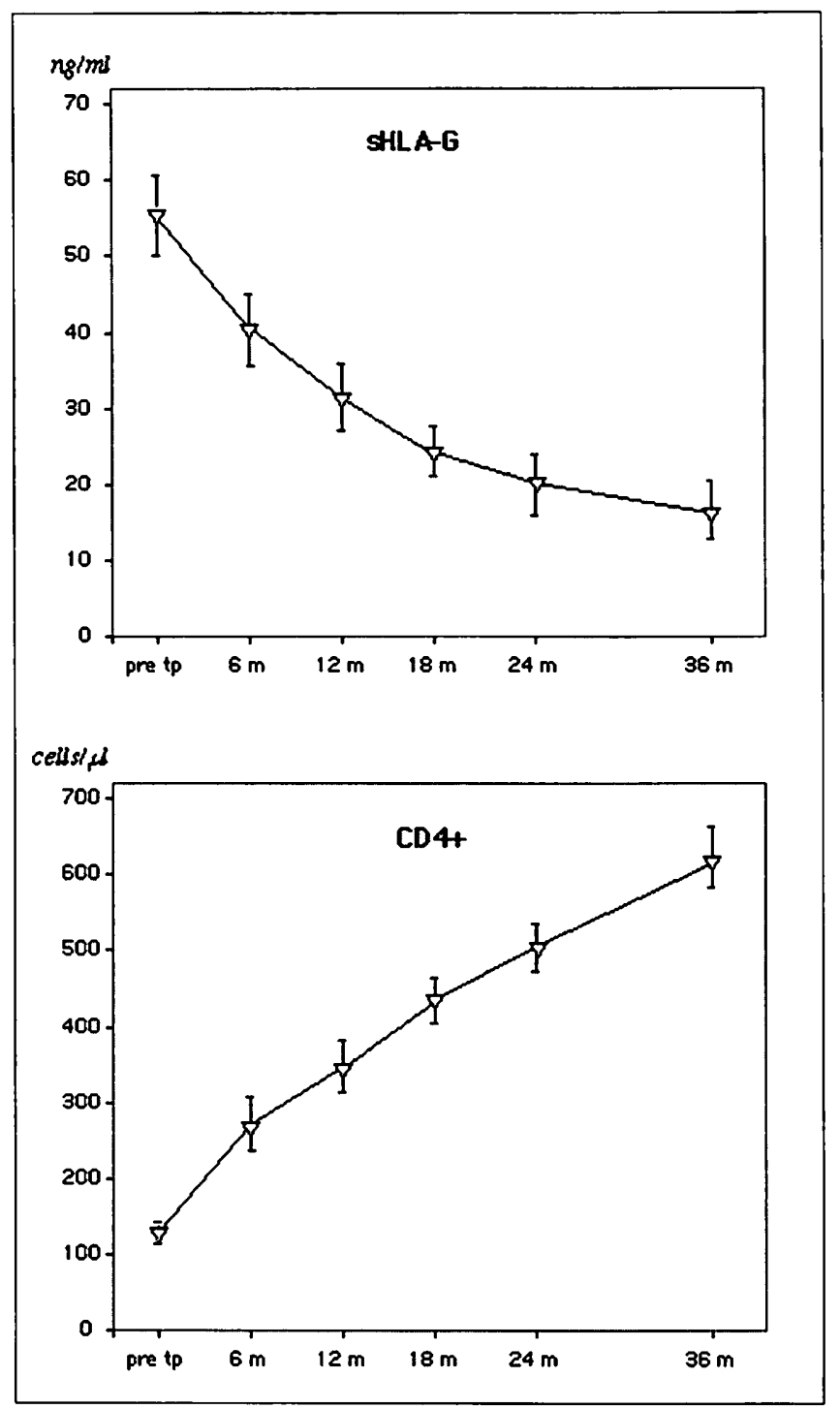

Figure 2. Inverse correlation between SHLA-G serum levels and absolute number of CD4+ T-lymphocytes during antiretroviral treatment $(\mathrm{m}$ : months).

\section{Discussion}

HLA-G is a non-classical HLA class I molecule with multiple immunoregulatory properties. Main function is to abrogate maternal NK cell activity against foetal tissue and to establish immune tolerance at the maternal-foetal interface $[5,6]$. sHLA-G molecule levels may increase in physiological and pathological conditions such as pregnancy, acute rejection episodes following organ allografts, acute graft-versus-host disease following bone marrow transplantation, autoimmune diseases, malignant melanoma and viral infections [11,12].Membrane expression of HLA-G molecules is increased on monocytes and Tymphocytes obtained from HIV-positive patients [13] and elevated levels 
of sHLA-G1 and sHLA-G5 antigens are detected in the blood of HIV-infected patients with or without visceral Leishmaniasis, contributing to Leishmania immune evasion in HIV-infected patients [14]. It has been demonstrated that elevated levels of soluble HLA-G in HIV-1 infection result from increased secretion of intracellularty stored HLA-G molecules in monocytes and dendritic cells and interfere, by interaction with the HLA class I receptor LLRB2 (ILT4), with myeloid dendritic cells function inhibiting their antigen-presenting properties and enhancing their secretion of proinflammatory cytokines [15]. Serum levels of sHLA-A, -B, $-\mathrm{C}$ and sHLA-G molecules are significantly elevated in HIV-infected subjects as compared with healthy controls and significantly decrease after 36 months of HAART correlating with the decrease of plasma HIV-RNA level, with the increase of CD4+ T-lymphocyte number and with CD8/CD38+ and CD8/ HLA class $\|+T$ cells number [9-10]. We have hypothesized that elevated levels of sHLA antigens may reflect their accelerated turnover from peripheral blood mononuclear cells activated in vivo during HIV infection and opportunistic infections contributing in determining the immune deficient state of AIDS patients. We have measured sHLA-G serum levels in patients with five different AIDS-defining conditions before and during HAART and correlated them with virological and imunological parameters of response to treatment. Results indicate that sHLA-G serum levels at baseline were significantly higher in AIDS patients as compared to healthy controls. sHLA-G levels were significantly higher in patients with opportunistic infections (i.e. Candida esophagitis, gastrointestinal Cryptosporidiosis, and Pneumocystis jirovecii pneumonia) and neoplasia (i.e. Kaposi's sarcoma) as compared to subjects with the wasting syndrome, suggesting that infections and neoplasms may represent conditions which trigger the shedding of elevated amounts of sHLA-G molecules. SHLA-G molecules decreased after 36 months of HAART correlating with the increase of CD4+T cells. Mechanism(s) undertying the elevated levels of sHLA molecules in AIDS patients might be attributable to the modulation by interferons and interleukin-10, which are potent inducers of HLA-G expression [17,18].

It has been shown that sHLA-G molecules inhibit the activity of CD8+ antigen-specific cytotoxic T cells, trigger apoptosis in $\mathrm{CD} 8+\mathrm{T}$ and NK cells, block proliferation of CD4+T-lymphocytes and induce immunosuppressive T-cells [20,21]. Opportunistic infections and neoplasms may increase the secretion of sHLA-G molecules contributing to the immune deficient state of AIDS patients. By contrast, HAART treatment could positively affect immune reconstitution also by decreasing the circulating amount of sHLA-G molecules.

\section{References}

[1] Ploegh H.L, Orr H.T., Strominger J.L 1981. Major histocompatibility antigens: the human (HLA-A, $-B,-C)$ and murine $(H-2 K, H-2 D)$ class $I$ molecules. Cell, 24: 287-299.

[2] OCallaghan C.A., Bell J.L. 1998. Structure and function of the human MHC class lb molecules HLA-E, HLA-F and HLA-G. Immunol. Rev., 163:129-138.

[3] Krangel M.S. 1987.Two forms of HLA class I molecules in human plasma. Hum. Immunol., 20:155-165.

[4] TabayoyongW.B., Zavazava N. 2007. Soluble HLA revisited. Leuk Res., 31:121-125.
[5] Favier B., LeMaoult ]., Rouas-Freiss N., Moreau P., Menier P., Carosella E.D. 2007. Research on HLA-G: an update. Tissue Antigens, 69: 207211.

[6] Carosella E.D., Favier B., Rouas-Freiss N., Moreau P., LeMaoult ]. 2008. Beyond the increasing complexity of the immunomodulatory HLA-G molecule. Blood, 111:4862-4870.

[7] Lifson A.R., Hessol N.A., Buchbinder S.P., O'Malley P.M., Barnhart L, Segal M., Kats M.H., Holmberg S.D. 1992. Serum $\beta_{2}$-microglobulin and prediction of progression to AIDS in HIV infection. Lancet, 339: 1436-1440.

[8] Puppo F., Brenci S., Lanza L, Bosco O., Imro M.A., Scudeletti M., Indiveri F., Ferrone S. 1994. Increased level of serum HLA class I antigens in HIV infection. Correlation with disease progression. Hum. Immund., 40: 259-266.

[9] Murdaca G., Contini P.,Setti M., Cagnati P.Villa R., Lantieri F., Indiveri F., Puppo F. 2007. Behavior of serum human major histocompatibility complex class I antigen levels in human immunodeficiency virusinfected patients during antiretroviral therapy: correlation with clinical outcome. Hum. Immunol., 68:894-900.

[10] Murdaca G., Contini P., Setti M., Cagnati P., Lantieri F., Indiveri F., Puppo F.2009. Behavior of non classical soluble HLA class $G$ antigens in human immunodeficiency virus 1 -infected patients before and after HAART: comparison with classical soluble HLA-A, -B, -C antigens and potential role in immune reconstitution. Clin. Immunol., 133:238-244.

[11] Pistoia V., Morandi F.,Wang X., Ferrone S. 2007. Soluble HLA-G:Are they clinically relevant? Sem. Cancer Biol., 17:469-479.

[12] Fainardi E., Rizzo R., Melchiorri L., Stignani M., Castellazzi M., Tamborino C., Paolino E., Tola M.R., Granieri E., Baricordi O.R. 2008. CSF levels of soluble HLA-G and Fas molecules are inversely associated to MRI evidence of disease activity in patients with relapsing-remitting multiple sclerosis. Mult Scler., 14:446-454.

[13] Lozano J.M., Gonzalez R., Kindelan J.M., Rouas-Freiss N., Caballos R. Dausset J., Carosella E.D., Peña J. 2002 Monocytes and T lymphocytes in HIV-1-positive patients express HLA-G molecule.AIDS, 16:347351.

[14] Donaghy L., Gros F.Amiot F., Mary C., MaillardA., Guiguen C., Gangneux J.P. 2007. Elevated levels of soluble non-classical major histocompatibility class I molecule human leucocyte antigen (HLA)-G in the blood of HIV-infected patients with or without visceral leishmaniasis. Cin. Exp. Immunol., 147:236-240.

[15] Huang J., Burke P., Yang Y., Seiss K., Beamon J., Cung T.,Toth I., Pereyra F., Lichterfeld M.,Yu X.G. 2010. Soluble HLA-G inhibits myeloid dendritic cell function in HIV-1 infection by interactions with ILT4.). Virol.,84: 10784-10791.

[16] Lajoie J., Fontaine J.Tremblay C., Routy J.P., Poudrier J., Roger M. 2009. Persistence of high levels of blood soluble human leukocyte antigen-G is associated with rapid progression of HIV infection. AlDS, 23:1437-1440.

[17] Moreau P.,Adrian-Cabestre F., Menier C., GuiardV., Gourand L. Dausset J., Carosella ED. Paul P. 1999. IL-10 selectively induces HLA-G expression in human trophoblasts and monocytes. Int. Immunol., 11:803-811.

[18] Fan J., Bass H.Z., Fahey J.L 1993. Elevated IFN-gamma and decreased IL-2 gene expression are associated with HIV infection.J. Immunol., 151:5031-5040.

[19] Contini P., Ghio M., PoggiA., Filaci G., Indiveri F., Ferrone S., Puppo F. 2003. Soluble HLA-A, $-B,-C$ and $-G$ molecules induce apoptosis in T and NK CD8+ cells and inhibit cytotoxic T cell activity through CD8 ligation. Eur.]. Immunol., 33: 125-134.

[20] Contini P., Ghio M., Merlo M.. Poggi A., Indiveri F., Puppo F. 2005. Apoptosis of antigen-specific T lymphocytes upon the engagement of CD8 by soluble HLA Class I molecules is Fas Ligand/Fas mediated: evidence for the involvement of $\mathrm{p} 56^{\text {thk }}$, calcium calmodulin kinase II, and calcium-independent protein kinase $C$ signaling pathways and for NF-kB and NF-AT nuclear translocation. J. Immunol., 175: 7244-7254. 